\title{
Microstructure and Corrosion Behaviour of ZnNiP Thin Film Alloys in Deep Eutectic Solvent Ionic Liquids
}

\begin{abstract}
ELENA IONELA NEACŞU ${ }^{1}$, VIRGIL CONSTANTIN ${ }^{1 *}$, MARIAN BURADA ${ }^{2}$, CRISTINA DONATH $^{1}$, VASILE SOARE ${ }^{2}$, ANA-MARIA POPESCU ${ }^{1 *}$

${ }^{1}$ Ilie Murgulescu Institute of Physical Chemistry of the Romanian Academy, 202 Splaiul Independentei, 060021 , Bucharest, Romania

${ }^{2}$ National R\&D Institute of Nonferous and Rare metals-IMNR, 102 Biruintei Blvd., 077145, Pantelimon, Ilfov, Romania

Ternary ZnNiP alloy thin films were electroless deposited from aqueous chloride electrolytes on mild steel foils. The films were characterized by scanning electron microscopy (SEM) and dispersive X-ray microanalysis (EDAX). The corrosion behaviour of ZnNiP thin films alloys was investigated in two deep eutectic solvent ionic liquids (DES) with different chemical structure at $353 \mathrm{~K}$ and compared with corrosion in $3.5 \% \mathrm{NaCl}$ aqueous solution at $273 \mathrm{~K}$. The films were characterized by X-ray photoelectron spectroscopy (XPS) to determine their chemical composition in the initial stage and after corrosion. The nature of corrosion morfology has been investigated by and electron microscopy and XPS. The value of the lowest corrosion protection efficiency was of $48.14 \%$ and the highest value was of $77.96 \%$. The results confirmed the high corrosion resistance of ZnNiP alloy plated sheet in all ionic liquids systems tested and the results were corelated with corrosion data in aqueous solution. The passive layer consists of $\mathrm{Zn}$ and Ni oxides but also of the chemical compounds of nitrogen which were formed on the surface of the ZnNiP thin films during the corrosion process.
\end{abstract}

Keywords: ZnNiP thin films, Microstructure, Ionic liquids, Corrosion resistance, XPS

$\mathrm{ZnNiP}$ alloys are important in applications for anticorrosive protection of steel parts for energy systems, transportation, chemical equipment production, metallic constructions, etc. Zinc exhibits a very negative electrode standard potential $\left(\mathrm{E}_{0}=-0.76 \mathrm{~V}\right.$, measured $v s$. hydrogen normal electrode), thus being capable of acting as a sacrificial coating for plate. Ternary $\mathrm{ZnNiP}$ alloys were of special interest because of the corrosion resistance enhanced capability brought by an addition of $1-5 \% \mathrm{P}$ in $\mathrm{ZnNi}$ alloys. Anticorrosive $\mathrm{ZnNiP}$ thin films depositions can be performed both electrochemically as well as chemical plating (electroless deposition), [1-10]. The mechanism of incorporating phosphorus in the alloy is complex and it is based both on direct electrochemical reactions of $\mathrm{Ni}^{2+} \mathrm{and}$ $\mathrm{Zn}^{2+}$ reduction [11-13] and indirect electrochemical reactions, as $\mathrm{H}_{2} \mathrm{PO}_{2}^{-}$disproportionation reaction resulting in phosphorous incorporation in the cathodic deposited alloy. Many studies were done on the corrosion of these ternary alloys in aqueous media [14,15]. Ionic liquids (ILs) have been widely investigated for a variety of applications: the use as solvents for chemical synthesis media, for electrodeposition of metals electrolyte, for electrochemical devices and fluids for thermal storage [16]. As long as we know there are studies on obtaining ZnNiP from IL [17], but no studies on the corrosion behaviour of these ternary alloys in these media were reported in literature. The present study describes the experimental works performed for electroless obtaining of $\mathrm{ZnNiP}$ thin films on steel substrate from alkaline chloride aqueous solutions and the corrosion behaviour of these alloys in deep eutectic solvent ILs.

\section{Experimental part \\ Materials}

$\mathrm{ZnNiP}$ thin films were electroless deposited [samples $\mathrm{ZnNiP}(1), \mathrm{ZnNiP}(2)$ and $\mathrm{ZnNiP}(3)$ ] on low carbon steel substrate (composition $\mathrm{Fe}_{99.49}-\mathrm{C}_{0.0043}-\mathrm{Si}_{0.044}-\mathrm{Mn}_{0.41}-\mathrm{Ni}_{0.011}$ ). The carbon steel substrate was first polished with $\mathrm{SiC}$ paper from grade $\mathrm{O} 100$ to grade $\mathrm{O} 400$, and was subjected to a special surface finishing before deposition: cleaning in acetone, cleaning in an alkaline solution for $10 \mathrm{~min}$ at $353 \mathrm{~K}$, cleaning in $10 \mathrm{vol} . \% \mathrm{H}_{2} \mathrm{SO}_{4}$ solutions, for $30 \mathrm{~s}$, at $273 \mathrm{~K}$, electrocleaning in an alkaline solution for 20-25 min according to ASTM G1-03 (the current density was $10 \mathrm{~mA} \mathrm{~cm}$ ) [18]; after each step, the specimens were rinsed with deionized water. The thin film alloys preparation conditions are presented in Table 1.

\footnotetext{
*email:virgilconstantin@yahoo.com,popescuamj@yahoo.com
} 
Table 1

CHEMICAL COMPOSITION AND CONDITIONS OF THE AQUEOUS DEPOSITION BATH

\begin{tabular}{|c|c|c|c|c|c|c|c|}
\hline \multirow[t]{2}{*}{ Samples } & \multicolumn{5}{|c|}{ Chemical composition $\mathrm{g} / \mathrm{l}$} & \multirow[t]{2}{*}{$\mathrm{pH}$} & \multirow{2}{*}{$\begin{array}{c}\mathrm{T} \\
(\mathrm{K})\end{array}$} \\
\hline & $\begin{array}{l}\mathrm{NiCl}_{2} \\
\times 6 \mathrm{H}_{2} \mathrm{O}\end{array}$ & $\mathrm{ZnCl}_{2}$ & $\begin{array}{c}\mathrm{NaH}_{2} \mathrm{PO}_{2} \\
\times \mathrm{H}_{2} \mathrm{O}\end{array}$ & $\begin{array}{c}\mathrm{C}_{6} \mathrm{Na}_{3} \mathrm{H}_{5} \mathrm{O}_{7} \\
\times 51 / 2 \mathrm{H}_{2} \mathrm{O} \\
(\text { Sodium } \\
\text { citrate) }\end{array}$ & $\mathrm{NH}_{4} \mathrm{Cl}$ & & \\
\hline $\mathrm{ZnNiP}(1)$ & 47 & 10 & 45 & 4 & 26 & 9.5 & 358 \\
\hline $\mathrm{ZnNiP}(2)$ & 50 & 10 & 50 & 10 & 100 & 9.5 & 343 \\
\hline $\mathrm{ZnNiP}(3)$ & 135 & 62 & 20 & 21 & 22 & 9.0 & 303 \\
\hline
\end{tabular}

The deposition time was kept constant at $120 \mathrm{~min}$. All solutions were prepared with analytical grade reagents (obtained from Merck, USA) dissolved in triply distilled water. After the electroless deposition, the samples were washed with distilled water and dried with hot air. All experiments were carried out in duplicate and the ability to reproduce these sample was found satisfactory. Film thickness is determined using the equation: $h=G / 2 \rho S$, where $h$ is the film thickness $(\mu), \mathrm{G}$ is the weight of the deposited alloy $(\mathrm{g}), \rho$ is the density of Zn-Ni-P alloy $\left(\approx 8.5 \mathrm{~g} \mathrm{~cm}^{-3}\right)$ and $\mathrm{S}$ is the steel sample surface area $\left(4 \mathrm{~cm}^{2}\right)$.

\section{Surface morphology and chemical composition}

The elemental distribution and surface morphology of deposits were examined using EDAX integrated with a scanning electron microscope (SEM) Philips XL-30 .To ensure accuracy, EDAX analysis was done at several points on the surface of the substrate. The accuracy of the measurements for the equipment used was rated as $\pm 0.1 \mathrm{wt} . \%$.

XPS analysis was performed before and after corrosion in order to know the morphology and surface composition of the studied samples. XPS measurement of the obtained thin films was carried out on a Quantera SXM equipment, with a base pressure in the analysis chamber of $10^{-9}$ Torr. The X-ray source was Al-K $\alpha$ radiation $(1.4866 \mathrm{keV}$, monochromatized), and the overall energy resolution is estimated at $0.65 \mathrm{eV}$ by the full width at half maximum (FWHM) of the Au4f $\mathrm{f}_{7 / 2}$ line. In order to take into account the charging effect on the measured binding energies (BE), the spectra were calibrated using the $\mathrm{C} 1 \mathrm{~s}$ line $(\mathrm{BE}=284.8 \mathrm{eV}, \mathrm{C}-\mathrm{C}(\mathrm{CH}) \mathrm{n}$ bondings) of the adsorbed hydrocarbon on the sample surface [19]. XPS data base[20,21] was used for identifying the deconvoluted peaks. The sensitivity of the XPS method is in the range of $10^{-3}-10^{-4}$ of a monolayer ( $\mathrm{ppb}$ ), so it is expected to have some differences from EDAX results. Quantitative analysis (relative concentrations) has estimated in the range of $\pm 10 \%$, while the accuracy for $\mathrm{BE}$ assignments was $\pm 0.2 \mathrm{eV}$.

\section{Corrosion test}

Corrosion behavior of the $\mathrm{ZnNiP}$ thin film coatings was evaluated through potentiodynamic polarization tests using a PARSTAT 2273 potentiostat/galvanostat with a "Power Corr" software. The polarization tests were conducted in two systems of deep eutectic solvent (DES) ILs based on choline chloride [(2-hydroxyethyl) trimethylammonium chloride]. All reagents (Choline chloride (ChCl, Sigma Aldrich >99\%), urea (Sigma Aldrich >99) and ethylene glycol (Fluka $>99.5 \%$ ) were used as purchased without recrystallization or drying, in order to simulate a more appropriate technological process for future industrial use. Popular names of DESs that are used throughout this work are Reline200 and Etaline100. Both are formed by mixing and heating $\mathrm{ChCl}$ with urea or ethylene glycol in a molar ratio corresponding to binary eutectic [respectively ChCl-urea (1:2 molar ratio), for sample ZNP(1), ZNP(2) and ChClethylene glycol (1:1M), for sample ZNP(3) ] at $353 \mathrm{~K}$ until homogenous and color less liquid was formed. The corrosion experiments were catrried aut in both Reline200.and Etaline100 aerated solutions at $353 \mathrm{~K}$. The obtained results were compared with the results obtained for corrosion resistance of these samples in $3.5 \mathrm{wt} . \% \mathrm{NaCl}$ aqueous solution. A three electrode configuration assembed in a thermostatic glass cell was used. The specimen with an exposed area of $1 \mathrm{~cm}^{2}$ was used as working electrode, glassy carbon (GC) as counter electrode and an $\mathrm{Ag}$ wire (Johnson Mathew) as a quasi reference electrode. For the experiments in $3.5 \mathrm{wt} \% \mathrm{NaCl}$ the SCE reference electrode was used. The cell assembly was located at a Faraday cage to prevent electrical interferences. The samples were immersed in the electrolyte before the tests started and were allowed to reach equilibrium, which usually took around $20 \mathrm{~min}$. Linear polarization curves were obtained by sweeping the electrode potential in the range of $\pm 20 \mathrm{mV} v s$. opencircuit potential (OCP) starting from cathodic area, after a constant value of OCP was achieved (up to $30 \mathrm{~min}$ ) [22]. Also, Tafel polarization experiments were performed with a constant scan rate of $0.166 \mathrm{mVs}^{-1}$, while the potential was being shifted within $\pm 250 \mathrm{mV}$ versus $\mathrm{E}_{\mathrm{OCP}}[23,24]$. Cathodic and anodic polarization was performed independently. 


\section{Results and discussions}

Surface morphology and elemental analysis of the ZnNiP thin film alloys

The obtained measured thickness of the studied samples was: $15 \mu \mathrm{m}$ for $\mathrm{ZnNiP}(1), 10 \mu \mathrm{m}$ for $\mathrm{ZnNiP}(2)$ and $32 \mu \mathrm{m}$

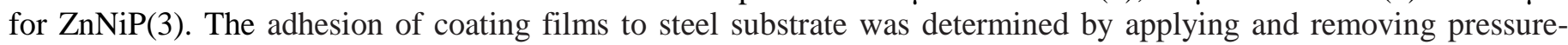
sensitive tape over cuts made in the film in accordance with ASTM D3359-09e2 [25]. The obtained results were: class 4B for $\mathrm{ZnNiP}(1)$, class $3 \mathrm{~B}$ for $\mathrm{ZnNiP}(2)$ and class $1 \mathrm{~B}$ for $\mathrm{ZnNiP}(3)$. The cross section microstructures of these samples are presented in Figure 1.

The morphology of the films is show in Figure 2, showing a uniform, homogenous and non porous deposit. The SEM images illustrate a "cauliflower" point-shaped spear specimen for the sample ZnNiP(1), with very large structures for the sample $\mathrm{ZnNip}(2)$ and a small, granular and multi-layered hollow structure for the sample $\mathrm{ZnNiP}(3)$.

For all samples on the EDAX spectra we have found the main constituents of the respective alloy to be $\mathrm{Zn}, \mathrm{Ni}, \mathrm{P}$. Also, in all samples was found Fe (from the support on which the alloy was deposited) which means that the formed $\mathrm{ZnNiP}$ film is very thin. With regard to the $\mathrm{ZnNiP}(3)$ sample, it also shows an $\mathrm{O}$ content, which shows that the coverage is not very pure. We will demonstrate later that EDAX data are well related with XPS data.

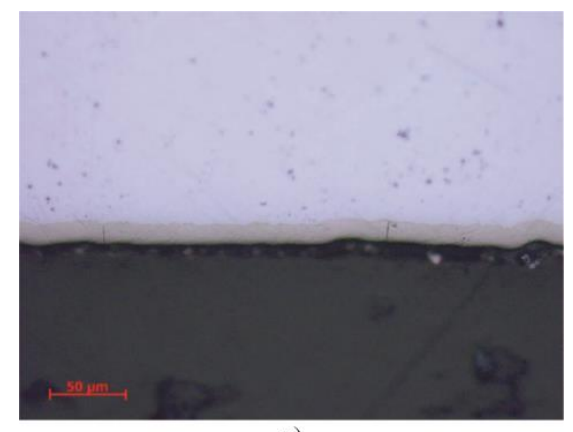

a)

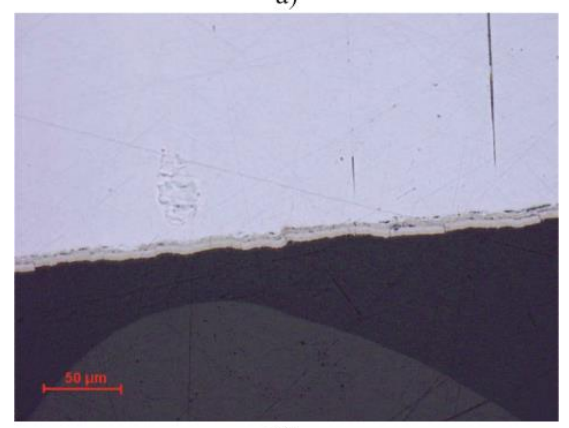

b)

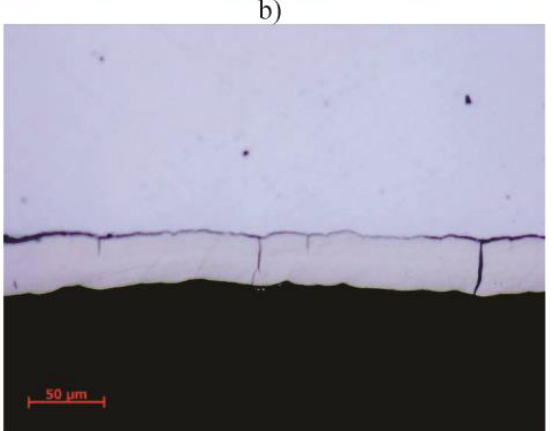

c)
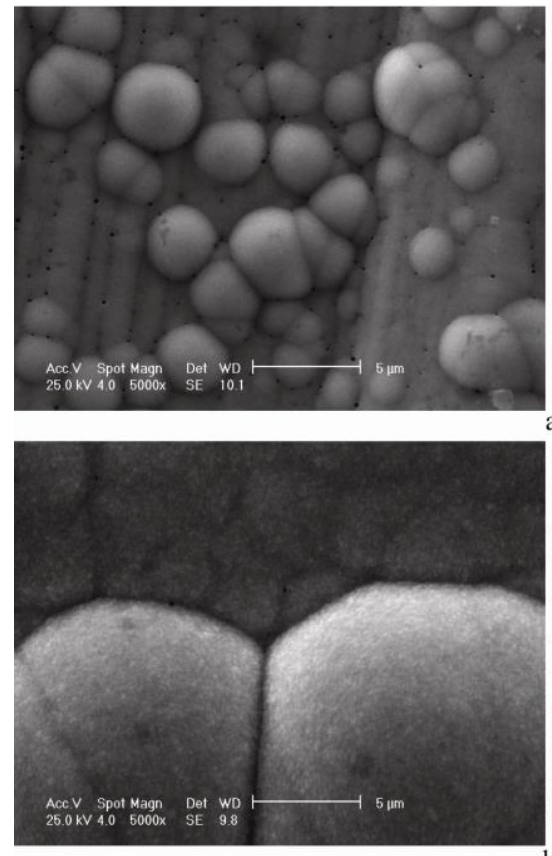

a)
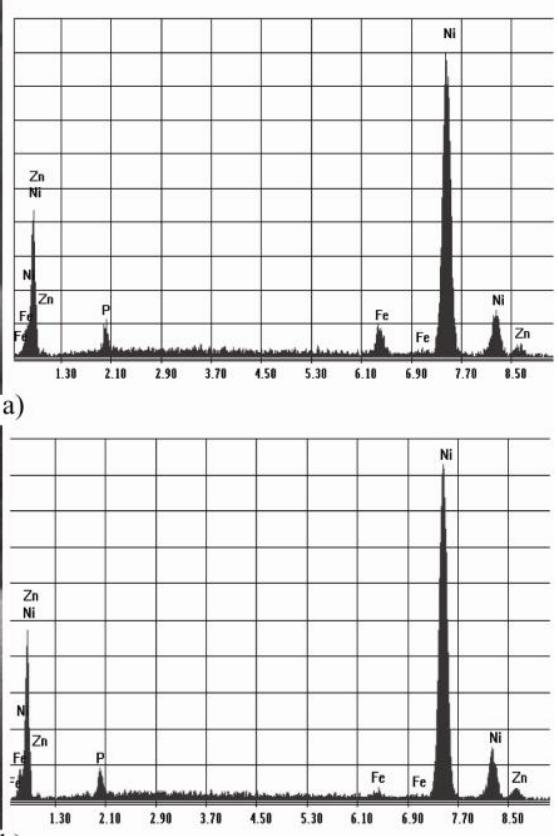
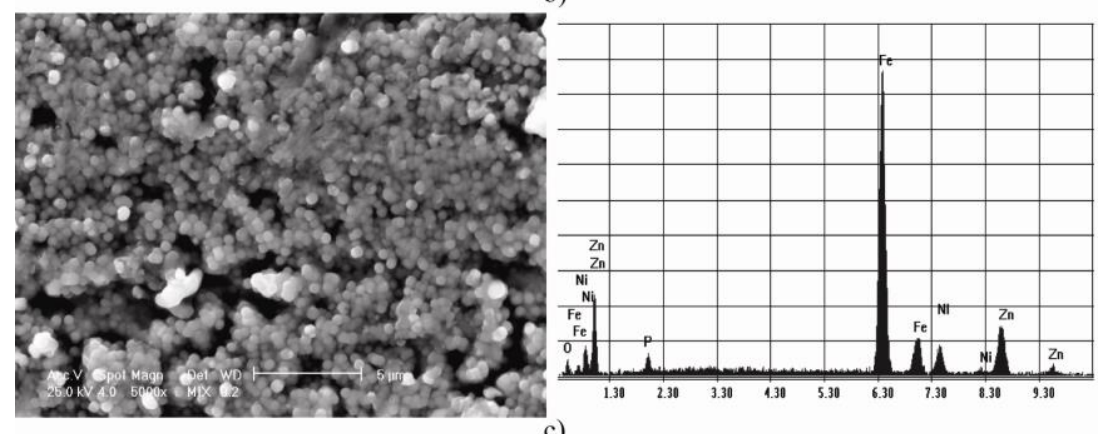

Fig. 1 Microstructures of ZnNiP samples deposited electrolessly in chloride aqueous medium: a) $\mathrm{ZnNiP}(1)$, b) $\mathrm{ZnNiP}(2)$, c) $\mathrm{ZnNiP}(3)$
Fig. 2 The surface morphology (SEM images and EDAX spectra) of the ZnNiP thin films deposited on the steel substrate for the samples: a) $\mathrm{ZnNiP}(1)$,

b) $\mathrm{ZnNiP}(2)$ and c) $\mathrm{zNnIp}(3)$

\section{Corrosion properties determined by potentiodynamic polarization}

Comparative potentiodynamic polarization studies for uncoated carbon steel and carbon steel coated with $\mathrm{ZnNiP}$ alloy were carried out in order to evaluate the corrosion rate and chemical resistance in two systems of ILs [ChCl-urea (1:2 molar ratio) and ChCl-ethylene glycol (1:1 molar ratio)]. The open circuit potential (OCP) was evaluated for quantitative evaluation of the corrosion process. Linear polarization curves (not shown) and Tafel potentiodynamic polarization curves (Figure 3) were plotted as specific electrochemical procedure, which permitted the establishing of 
the polarization resistance $\left(\mathrm{R}_{\mathrm{p}}\right)$, corrosion potential $\left(\mathrm{E}_{\text {corr }}\right)$, corrosion current $\left(\mathrm{i}_{\mathrm{cor}}\right)$, corrosion rate $(\mathrm{CR})$ and protection efficiency (PE) [26,27].

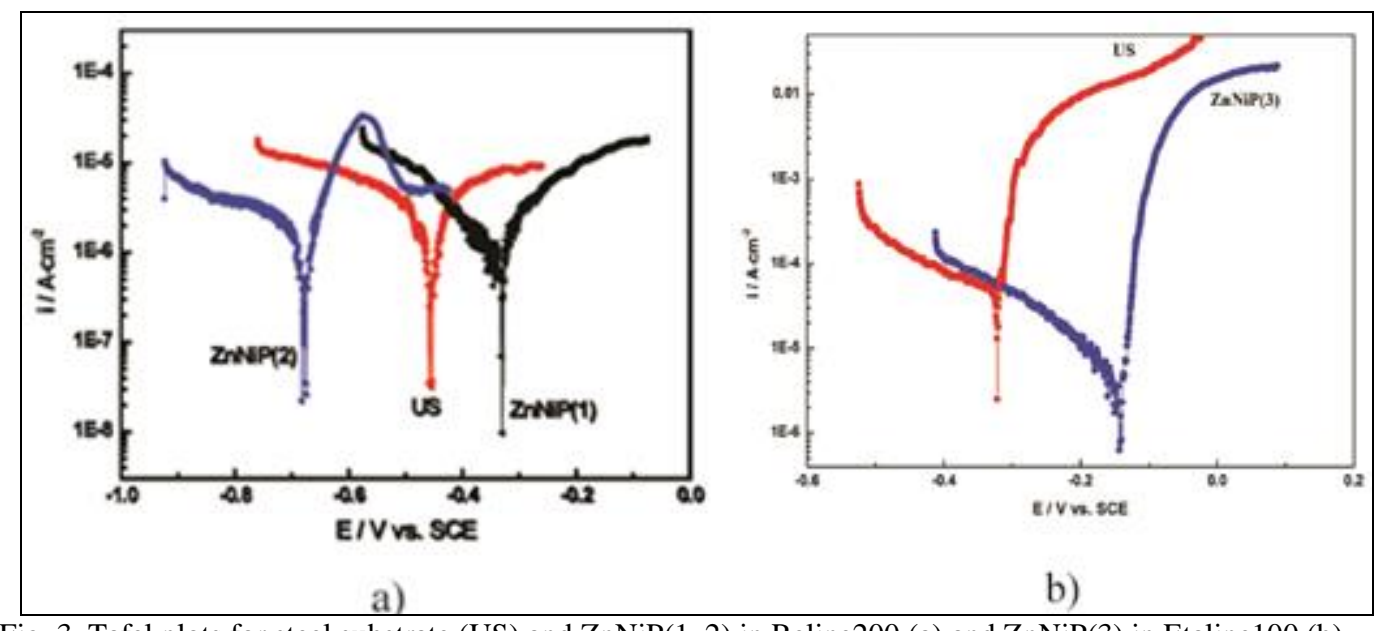

Fig. 3. Tafel plots for steel substrate (US) and ZnNiP(1, 2) in Reline200 (a) and ZnNiP(3) in Etaline100 (b)

The corrosion parameters obtained are presented in Table 2. For comparison of the results obtained in Ils and aqueous media, the same samples were also subjected to corrosion process in $3.5 \mathrm{wt} \% \mathrm{NaCl}$ (Table 3). For a given electrolyte solution, the OCP is dependent on the characteristics of resulted oxide, such as oxide thickness, chemical composition, electrical conductivity, structure, etc. At the initial time of immersion in Reline 200 environment the studied alloys present OCP potential values varying from $-0.538 \mathrm{~V}$ for uncoated steel (US) sample to $-0.381 \mathrm{~V}$ for $\mathrm{ZnNiP}(1)$ and $-0.693 \mathrm{~V}$ for $\mathrm{ZnNiP}(2)$ sample, while for the immersion in Ethaline100 the OCP values were $-0.295 \mathrm{~V}$ for steel sample and $-0.186 \mathrm{~V}$ for $\mathrm{ZnNiP}(3)$ sample. Most rapid evolution of OCP potential occurs during the first 7-10 minutes of immersion, while further potential evolution becomes slower and OCP values do not change significantly, having a slow monotonous shift towards more positive values. The values of OCP for the studied $\mathrm{ZnNiP}$ alloys depend strongly of the zinc content in the alloy, but all OCP values of the studied ZnNiP samples in the two ILs exhibited more positive potentials than for carbon steel substrate (US). The time evolution of OCP indicates that the $\mathrm{ZnNiP}$ film is thin and consequently becomes vulnerable toward penetration of $\mathrm{Cl}^{-}$ions. Also, we noticed slight oscillations of OCP in time. We assumed that these OCP oscillations may result from chemical interactions between chloride ions and the structured passive film. As in all samples the nickel content is higher than 73 wt.\%, this behaviour may be considered as depending strongly on zinc and phosphorous content in the alloy.

Analyzing the data in Table 2 we can observed that the unprotected steel (US) sample has OCP potentials more positive in ionic liquids compared to aqueous solution, having in $\mathrm{ChCl}$-ethylene glycol an the most positive value.

Table 2

THE CORROSION PARAMETERS MEASURED AND CALCULATED FOR THE STEEL SUBSTRATE (US) AND THE STUDIED ZnNiP SAMPLES IN RELINE 200 AND ETHALINE 100 AT $353 \mathrm{~K}$

\begin{tabular}{|ccccccc|}
\hline Sample & $\begin{array}{c}\text { EocP } \\
(\mathrm{V})\end{array}$ & $\begin{array}{c}\mathrm{R}_{\mathrm{p}} \\
\left(\Omega \mathrm{cm}^{2}\right)\end{array}$ & $\begin{array}{c}\mathrm{E}_{\text {corr }} \\
(\mathrm{V})\end{array}$ & $\begin{array}{c}\mathrm{i}_{\text {corr }} \\
\left(\mathrm{A} \cdot \mathrm{cm}^{-2}\right)\end{array}$ & $\begin{array}{c}\mathrm{CR} \\
\left(\mathrm{mm} \cdot \mathrm{y}^{-1}\right)\end{array}$ & PE (\%) \\
\hline US/Reline200 & -0.512 & 166.135 & -0.453 & $2.903 \cdot 10^{-8}$ & 0.0217 & 0 \\
ZnNiP(1) & -0.326 & 3219.15 & -0.325 & $8.931 \cdot 10^{-9}$ & 0.0048 & 77.96 \\
ZnNiP(2) & -0.674 & 2273.83 & -0.677 & $2.427 \cdot 10^{-8}$ & 0.0081 & 62.72 \\
US/Etaline100 & -0.274 & - & -0.318 & $9.435 \cdot 10^{-6}$ & 0.0108 & 0 \\
ZnNiP(3) & -0.162 & - & -0.450 & $6.441 \cdot 10^{-8}$ & 0.0056 & 48.14 \\
\hline
\end{tabular}

EOCP $=$ open potential (rest potential); $\mathrm{R}_{\mathrm{p}}=$ polarization resistance; $\mathrm{E}_{\mathrm{corr}}=$ corrosion potential; $\mathrm{i}_{\text {corr }}=$ corrosion current density; $\mathrm{CR}=$ corrosion rate; $\mathrm{PE}(\%)=$ protection efficiency

Table 3

THE CORROSION PARAMETERS CALCULATED FOR THE ZnNiP SAMPLES AND FOR THE UNPROTECTED STEEL SUPORT (US) IN 3.5\% NaCl AQUEOUS SOLUTION AT $298 \mathrm{~K}$

\begin{tabular}{|cccccc|}
\hline Sample & $\begin{array}{c}\text { EocP } \\
(\mathrm{V})\end{array}$ & $\begin{array}{c}\mathrm{E}_{\text {corr }} \\
(\mathrm{V})\end{array}$ & $\begin{array}{c}\mathrm{i}_{\text {corr }} \\
\left(\mathrm{A} \cdot \mathrm{cm}^{-2}\right)\end{array}$ & $\begin{array}{c}\text { CR } \\
\left(\mathrm{mm} \cdot \mathrm{y}^{-1}\right)\end{array}$ & $\begin{array}{c}\text { PE } \\
(\%)\end{array}$ \\
\hline $\mathrm{US} / \mathrm{NaCl}$ & -0.54 & -0.71 & $8.96 \cdot 10^{-6}$ & 0.2104 & - \\
$\mathrm{ZnNiP}(1)$ & -0.51 & -0.74 & $2.72 \cdot 10^{-6}$ & 0.0639 & 69.63 \\
& & & & & 13.35 \\
$\mathrm{ZnNiP}(2)$ & -0.53 & -0.37 & $17.72 \cdot 10^{-6}$ & 0.1823 & \\
& & & & & \\
\end{tabular}

$\mathrm{E}_{\mathrm{OCP}}=$ rest potential; $\mathrm{E}_{\mathrm{corr}}=$ corrosion potential; $\mathrm{i}_{\text {corr }}=$ corrosion current density; $\mathrm{CR}=$ corrosion rate; $\mathrm{PE}=$ protection efficiency 
As regarding the studied alloy samples the $\mathrm{ZnNiP}(2)$ which has a more negative $\mathrm{E}_{\mathrm{OCP}}$ in Reline200 compared to that of US, this can suggest that $\mathrm{ZnNiP}(2)$ sample could function as a sacrificial layer for steel. From the evolution of the Tafel curves it is clear that the samples have the same aspect as the sample US, i.e. they show cathodic protection with anodic polarization, but have more positive corrosion potential $[\mathrm{ZnNiP}(1)$ and $\mathrm{ZnNiP}(3)]$ or more negative [ZnNiP(2)] with respect of the support steel. The evolution of corrosion currents also indicates the anticorrosive protection capacity, due to lower values than that for US, so the covered samples will have a corrosion protection capacity. By evaluating the corrosion behavior of $\mathrm{ZnNiP}$ in Reline200 (ChCl-Urea), we have found that the $\mathrm{ZnNiP}(1)$ sample has the lowest corrosion current extrapolated from the Tafel curves and implicitly the lowest corrosion rate. This sample also shows the highest polarization resistance calculated from the linear polarization curves. At the same time it is observed that the samples in the study have of lower corrosion current density in the ILs than in the aqueous solution, which is in line with the literature data regarding the alloy corrosion in ILs [28]. It should also be added that the $\mathrm{ZnNiP}(2)$ sample, although having a lower corrosion rate than that of the $\mathrm{ZnNiP}(1)$ sample, it shows a strong passivation process and even anodic transpassivation (Figure 3a), which suggest that this sample even worked as layer of sacrifice, producing steel protection by passivation. We can link this behavior to sample structure (Figure 2) and conclude that $\mathrm{ZnNiP}(1)$ sample with medium and homogeneous globular structures is more resistant to corrosion than that with very large globular structures, $\mathrm{ZnNiP}(2)$. With regard to the $\mathrm{ZnNiP}(3)$ sample, its structure with small coarse grains and many holes as well as with the presence of oxygen, favors the appearance of corrosion centers and thus explains the low corrosion resistance of this sample in both aqueous and ionic solutions. With respect to the $\mathrm{ZnNiP}(3)$ sample whose corrosion was studied in Etaline 100, it was found to have the most positively OCP potential $(-0.162$ $\mathrm{V})$. Considering that in a given corrosive environment an electrode with a more noble OCP being more thermodynamically stable than a less noble electrode, we can conclude that the stability of the $\mathrm{ZnNiP}$ alloy is better in $\mathrm{ChCl}$-EG than in ChCl-Urea. The corrosion currents obtained in this study are in good agreement with the values obtained in ionic liquids in general, i.e. samples have very small currents [29]. Due to the complexity of the ionic fluid structure, the cathodic processes which can occur on the surfaces of metallic materials are very difficult to predict as shown by the potential fluctuations in the curves of Figure 3. The corrosion sequence of ZnNiP samples in ionic liquids studied is Etaline100 > Reline 200. The passivation tendency of samples in Reline 200 may be due to the presence of urea. From the corrosion sequence we can conclude that the presence in ethylene glycol (1,2 ethanediol) is more damaging compared to urea due to the presence of $\mathrm{OH}$ groups. The corroded surface was observed visually and micrographically for the identification of formation of any white/red rust on the coating. Literature show that when $\mathrm{Zn}-\mathrm{Ni}$ alloy coatings are exposed to salt solutions, zinc hydroxide is found to form as corrosion product [30]. This product is known as "white rust" which bears the indication of corrosion. The same phenomenon we noticed when $\mathrm{ZnNiP}$ is exposed to salt solution.

The morpho-structural characterization by metallographic and visual microscopy (Figures 4 and 5) revealed structures with moderate deformation and low adherence, structures that are responsible for the behavior observed in electrochemical testing.
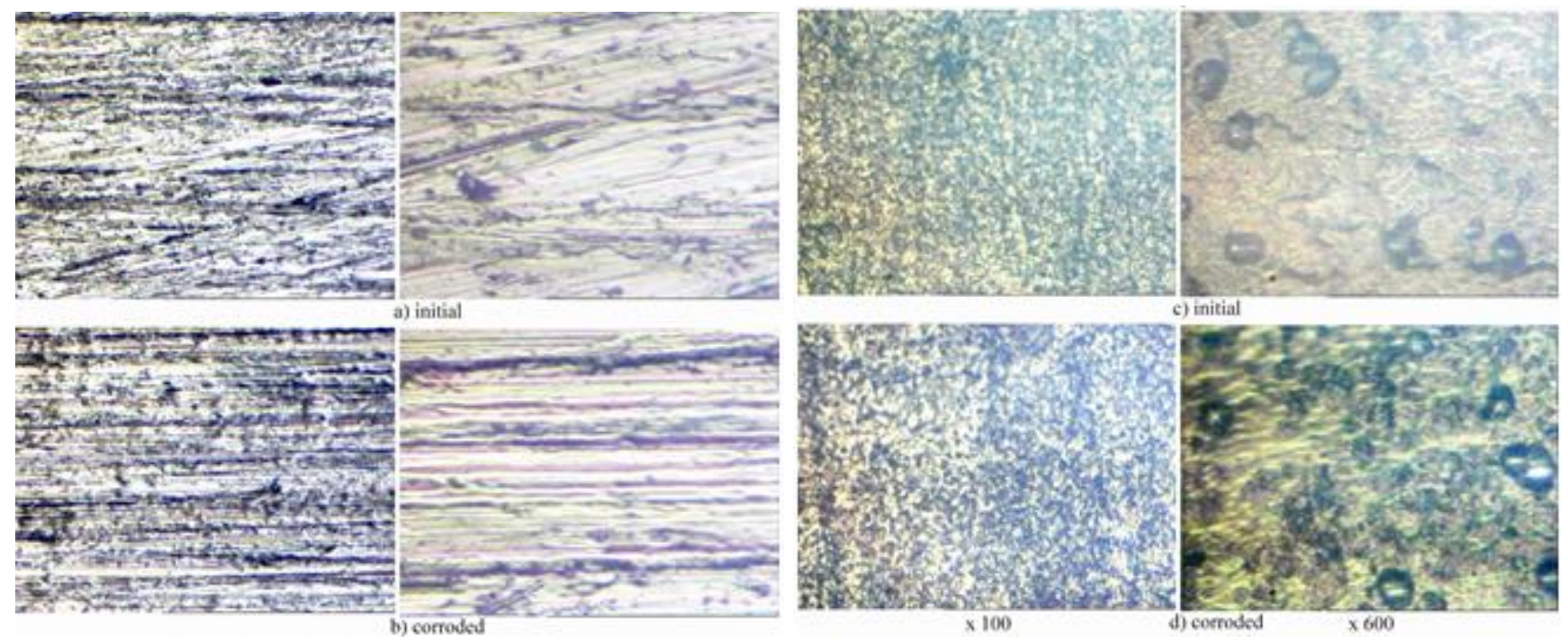

Fig. 4. Metallographic micrography with different magnifications for the samples $\mathrm{ZnNiP}(1)(\mathrm{a}, \mathrm{b})$ and $\mathrm{ZnNiP}(2)$ (c, d) before and after corrosion in Reline 200 at $353 \mathrm{~K}$ after $240 \mathrm{~min}$ 

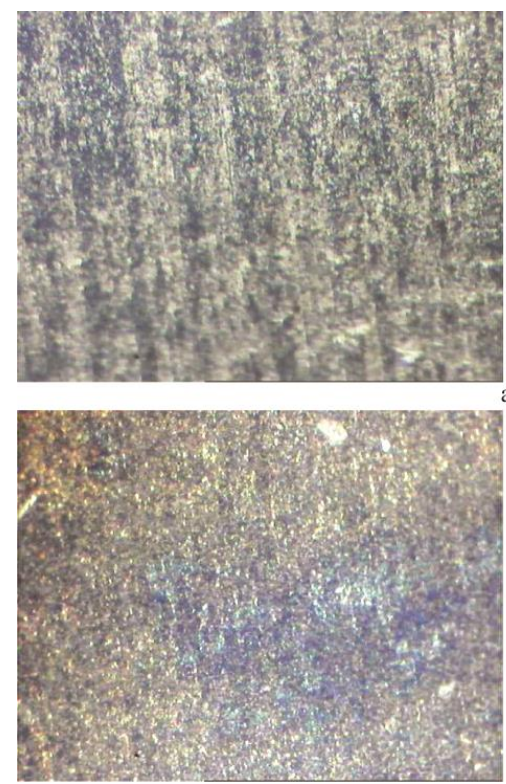

$\mathrm{x} 100$
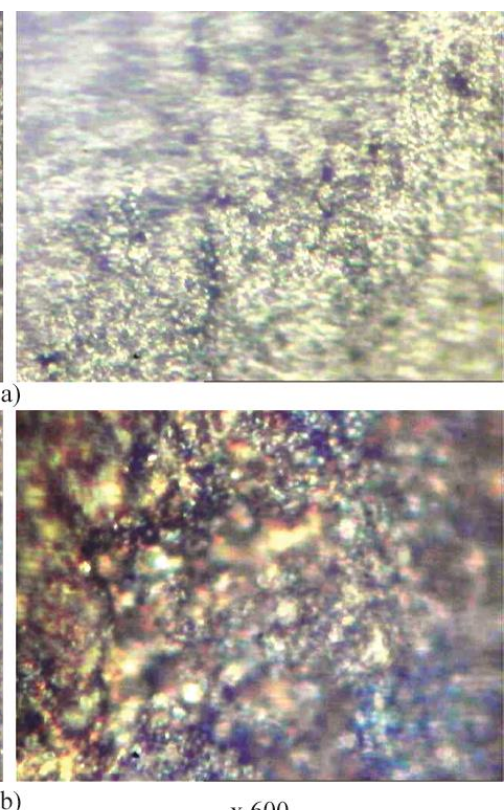

Fig. 5. Metallographic micrography with different magnifications for the sample $\mathrm{ZnNiP}(3)$ before (a) and after (b) corrosion in Ethaline 100 at $353 \mathrm{~K}$ after $240 \mathrm{~min}$

Surface chemical composition before and after corrosion test determined by XPS

XPS analysis was used to determine the chemical states of the elements present on the surface of the $\mathrm{Zn}-\mathrm{Ni}-\mathrm{P}$ thin film alloys deposited on steel substrate before and after the corrosion process. Survey (wide scan) XPS spectra were recorded to detect all the elements present on the surface $(<10 \mathrm{~nm})$. High resolution spectra were collected to find out the chemical bonding of the detected elements and for quantitative analysis, as well. Figure 6 shows the comparison of XPS spectra with the binding energies (BE) in the range of $0-1200 \mathrm{eV}$ for the studied samples before and after corrosion in the studied ionic liquids at $353 \mathrm{~K}$ for $240 \mathrm{~min}$. From the XPS spectra we can state the following: in all samples studied (regardless the ionic liquids used) the presence of Zn2p peak, ZnLMM Auger peak, Ni2p and P2p peaks are observed, in addition to the main transitions O1s, C1s and OKLL, in different proportions, which can be confirmed by both the high resolution spectra and the respective concentrations (Table 4). After corrosion, a small characteristic peak appears also for N1s. The binding energies from Table 5 are in concordance with Handbook of Xray photoelectron spectroscopy [31] and show peaks for the existence of $\mathrm{ZnO}, \mathrm{NiO} / \mathrm{Ni}_{2} \mathrm{O}_{3}, \mathrm{P}^{0} / \mathrm{P}$ organic and $\mathrm{N}$ in organic matrix.

Also, the oxygen peaks are composed from two contributions representing $\mathrm{O}^{2-}$ and $\mathrm{OH}^{-}$, a tiny amount of water for the polarized samples.The carbon detected on the surface comes from two sources: the surface is contaminated with unavoidable carbon from $\mathrm{CO}_{2}$ and hydrocarbon adsorbed on the outermost layer from ambient atmosphere; another reason is the presence of an aromatic compound $\left(\mathrm{C}_{6} \mathrm{Na}_{3} \mathrm{H}_{5} \mathrm{O}_{7} \times 5 \frac{1}{2} \mathrm{H}_{2} \mathrm{O} /\right.$ sodium citrate) used in the bath of electroless deposition.

The $\mathrm{ZnNiP(3)}$ sample has an approximate unitary $\mathrm{Zn} / \mathrm{Ni}$ ratio, suggesting that it might be less good in terms of corrosion resistance (already proven by the corrosion test).
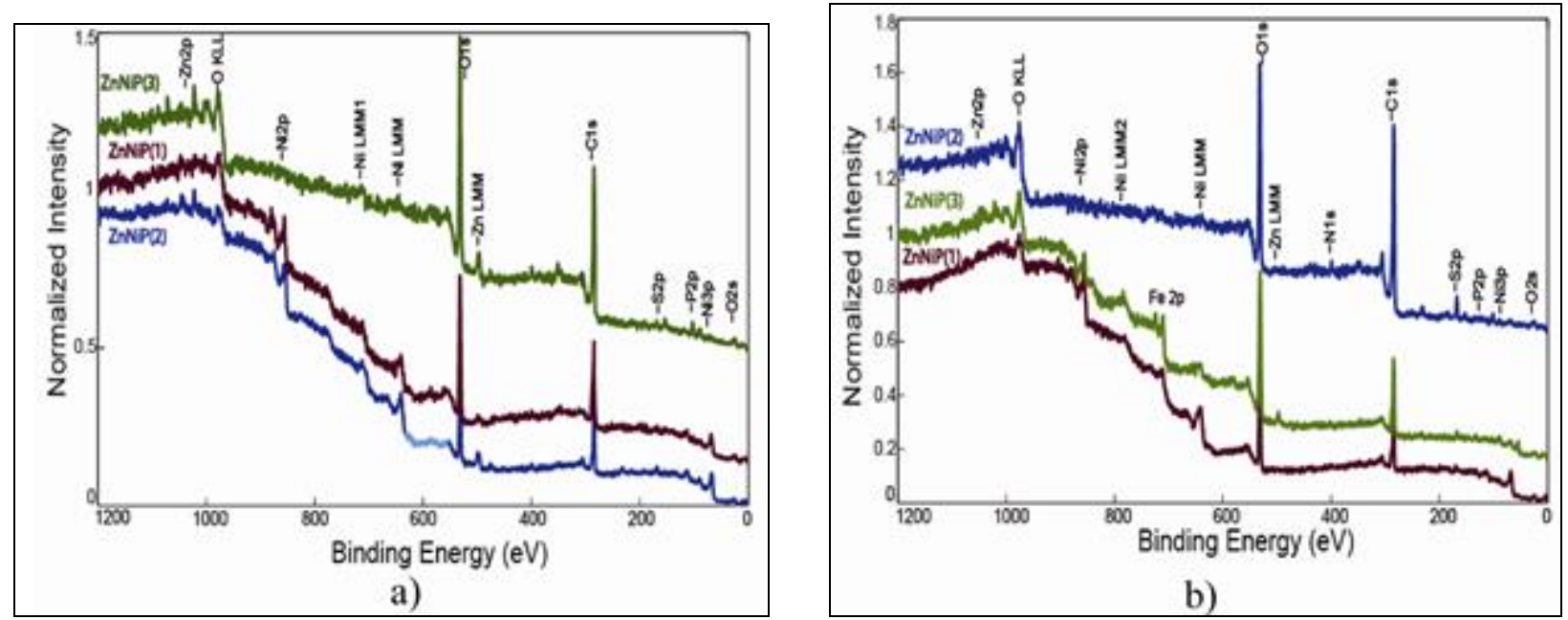

Fig. 6. XPS survey spectra for all samples $\mathrm{ZnNiP}(1), \mathrm{ZnNiP}(2)$ and $\mathrm{ZnNiP}(3)$ before (a) and after (b) corrosion at $353 \mathrm{~K}$ and $240 \mathrm{~min}$ 
Table 4

EXPERIMENTAL QUANTITATIVE XPS VALUES DETERMINED FOR THE INITIAL AND CORRODED ZnNiP COATING SAMPLES IN DESs, FOR 240 min AT 343K

\begin{tabular}{|c|c|c|c|c|c|c|}
\hline \multicolumn{7}{|c|}{ Element composition (wt.\%) } \\
\hline Samples & DES & $\mathrm{Zn}$ & $\mathrm{Ni}$ & $\mathrm{P}$ & $\mathrm{Fe}$ & $\mathrm{N}$ \\
\hline $\mathrm{ZnNiP}(1)$ initial & Reline & 2.85 & 92.35 & 4.80 & - & - \\
\hline $\mathrm{ZnNiP}(1)$ corroded & & 1.04 & 79.20 & 4.46 & 2.27 & 13.03 \\
\hline $\mathrm{ZnNiP(2)}$ initial & Reline & 13.22 & 85.31 & 1.47 & - & - \\
\hline $\mathrm{ZnNiP}(2)$ corroded & & 10.91 & 75.13 & 0.81 & 4.49 & 8.66 \\
\hline ZnNiP(3) initial & Ethaline & 32.55 & 60.07 & 7.38 & - & - \\
\hline $\mathrm{ZnNiP}(3)$ corroded & & 20.50 & 56.17 & 4.53 & 6.80 & 12.0 \\
\hline
\end{tabular}

Table 5

SUMMARY OF BINDING ENERGIES FOR THE INITIAL AND CORRODED SAMPLES

\begin{tabular}{|c|c|c|c|c|c|c|c|c|c|}
\hline \multicolumn{10}{|c|}{ Binding Energy $(\mathrm{eV})$} \\
\hline \multirow[t]{2}{*}{ Samples } & \multirow[t]{2}{*}{ Stage } & \multirow[t]{2}{*}{ DES } & $\mathrm{NiO}$ & $\mathrm{Ni}_{2} \mathrm{O}_{3}$ & $\mathrm{Ni}$ & $\mathrm{P}$ & $\mathrm{Zn}$ & $\mathrm{Zn}$ & $\mathrm{N}$ \\
\hline & & & $2 \mathrm{p}_{3 / 2,1 / 2}$ & $2 \mathrm{p}_{3 / 2,1 / 2}$ & (satellites) & $2 p$ & $2 \mathrm{p}_{3 / 2}$ & LMM & $1 \mathrm{~s}$ \\
\hline \multirow{4}{*}{$\mathrm{ZnNiP}(1)$} & \multirow[t]{2}{*}{ initial } & \multirow{4}{*}{ Reline } & 853.4 & 856.1 & 858.7 & 130.1 & 1022.2 & 497.5 & - \\
\hline & & & 870.1 & 873.2 & 876.7 & 133.6 & - & - & - \\
\hline & \multirow[t]{2}{*}{ corroded } & & 853.4 & 855.8 & 861.2 & 130.1 & 022.2 & 497.8 & 398.1 \\
\hline & & & 870.1 & 875.0 & 880.1 & 134.0 & - & - & 399.4 \\
\hline \multirow{4}{*}{$\mathrm{ZnNiP}(2)$} & \multirow[t]{2}{*}{ initial } & \multirow{4}{*}{ Reline } & 853.5 & 855.0 & 859.9 & 133.2 & 1022.0 & 498.3 & - \\
\hline & & & 870.5 & 873.9 & 875.7 & - & - & - & - \\
\hline & \multirow[t]{2}{*}{ corroded } & & 853.4 & - & 859.9 & - & 1022.3 & - & 398.8 \\
\hline & & & 870.5 & - & 875.4 & - & - & - & 400.5 \\
\hline \multirow[t]{4}{*}{$\mathrm{ZnNiP}(3)$} & \multirow[t]{2}{*}{ initial } & \multirow{4}{*}{ Ethaline } & 853.8 & 855.9 & 860.0 & 133.2 & 1022.1 & 497.9 & - \\
\hline & & & 871.0 & 873.1 & 877.3 & - & - & - & - \\
\hline & \multirow[t]{2}{*}{ corroded } & & 853.8 & 856.0 & 861.2 & 133.5 & 1022.3 & 497.2 & 398.2 \\
\hline & & & 871.1 & 875.2 & 880.1 & - & - & - & 400.3 \\
\hline
\end{tabular}

Figure 7, presents the registered XPS spectra for all elements: Ni, Zn, Zn LMM, P and $\mathrm{N}$ in all studied samples before and after corrosion. After corrosion the surface chemistry of the all samples shows significant changes by appearance a little peak characteristic of $\mathrm{Fe}$ because the $\mathrm{ZnNiP}$ deposits are very thin. The analysis of Table 4 shows that the amount $\mathrm{Fe}$ sample is higher $\mathrm{ZnNiP}(3)$, this sample had the lowest resistance to corrosion than the other two samples $\mathrm{ZnNiP}(1)$ and $\mathrm{ZnNiP}(2)$.

Thus, we can notice that while $\mathrm{P}$ relative concentration are in good agreement, the $\mathrm{Ni}$ and $\mathrm{Zn}$ relative concentration are different suggesting the diffusion of $\mathrm{Ni}$ from the surface into the subsurface region accompanied by segregation of $\mathrm{Zn}$ from subsurface region toward the outermost layer of the film. All elements decrease in the all sample, which presents an increased resistance to the corrosion process. 

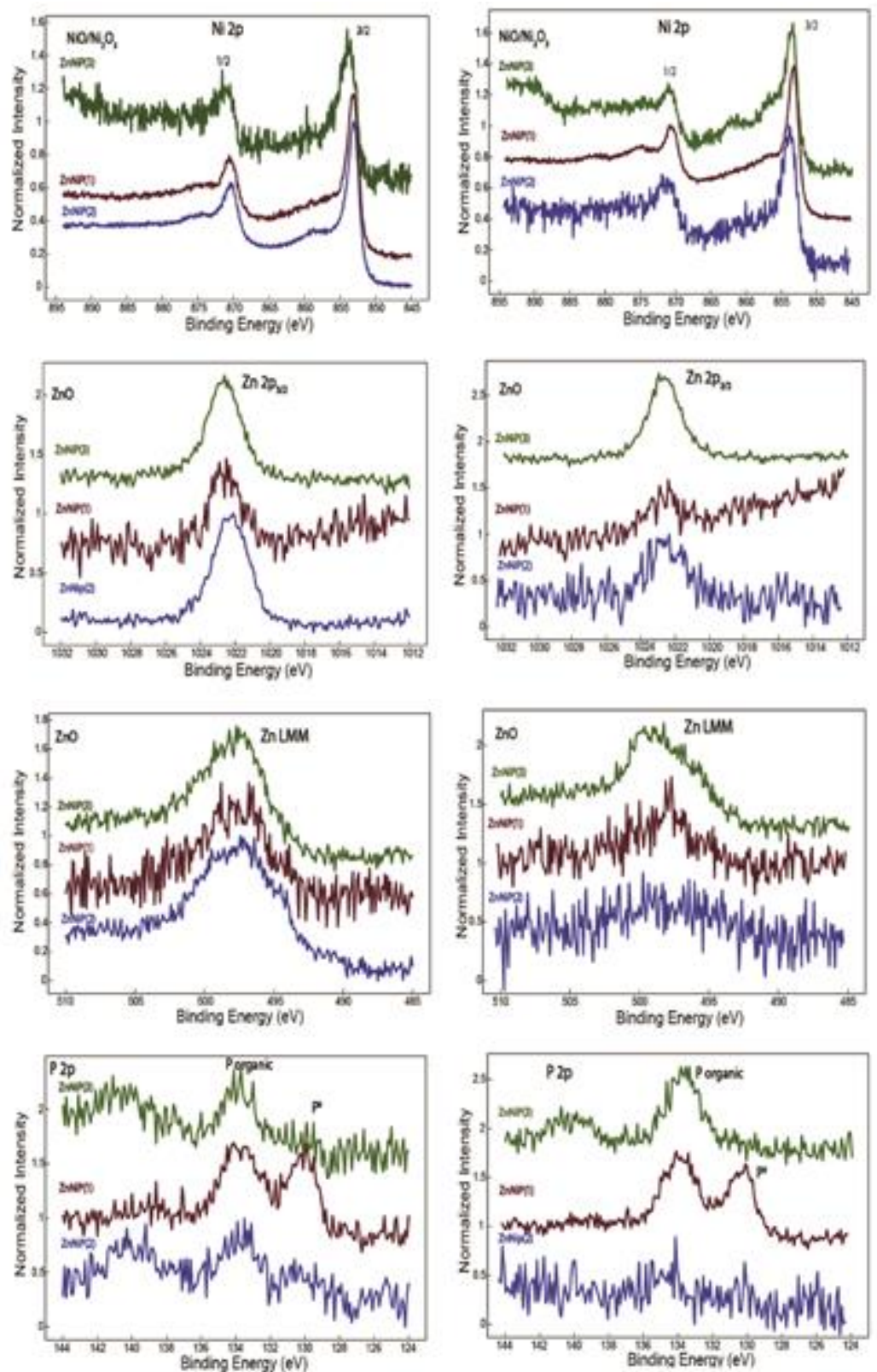

a)

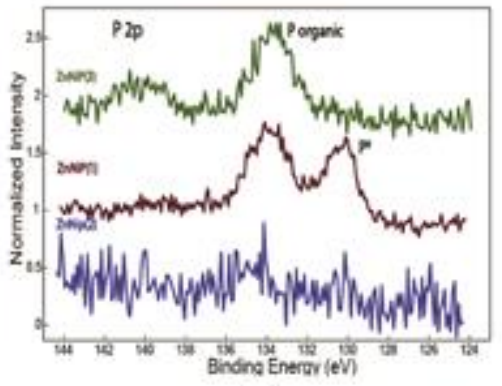

b)

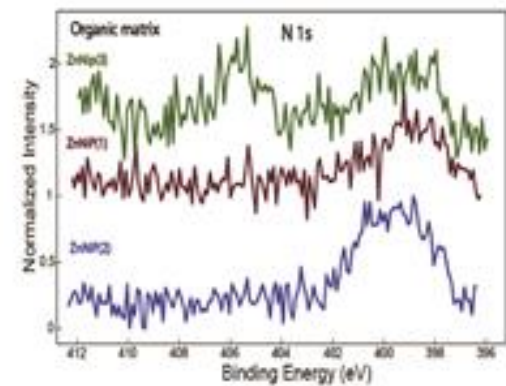

c)

Fig. 7. XPS spectra for all ZnNiP samples before (a) and after corrosion (b, c) in the used ILs

Figure 8 presents the deconvoluted spectra for $\mathrm{Zn}$ (both $2 \mathrm{p}$ and LMM-transitions) before and after corrosion. Both spectra for the $\mathrm{Zn} 2 \mathrm{p}_{3 / 2}$ and $\mathrm{Zn}$ LMM indicated the presence of $\mathrm{Zn}^{2+}$ ion as $\mathrm{ZnO}$ in all the film studied. Because it is practically impossible to detect a chemical shift between $\mathrm{Zn}^{0}$ and $\mathrm{Zn}^{2+}$ states in the photoelectron line $\mathrm{Zn} 2 \mathrm{p}_{3 / 2}$, we recorded also the Auger LMM transition. The BE values of $\mathrm{ZnO}$ characteristic energy were from 497.2 to $498.3 \mathrm{eV}$, which can be easily seen from Table 5. On the other hand, the specific BE values for metallic $\mathrm{Zn}$ are ranging from 495.1 to $495.9 \mathrm{eV}$. One can observe that only the $\mathrm{Zn} \mathrm{LMM}$ Auger transition exhibits a chemical shift of $\sim 2.5 \mathrm{eV}$ to higher $\mathrm{BE}$ for $\mathrm{Zn}$ in its +2 oxidation state as compared with $\mathrm{Zn}^{0}$. From the Auger LMM transition, it becomes clear that inclusion of $\mathrm{Zn}$ in the inital stage of $\mathrm{ZnNiP}$ electroless thin films is found to be in the +2 oxidation state as $\mathrm{ZnO}$ 
(497.5 eV - $498.3 \mathrm{eV}$ ). For the corroded samples the corrosion products of $\mathrm{ZnNiP}$ alloy platted steel were found to consist of zinc compound $\mathrm{ZnO}$ (at $497.2 \mathrm{eV}-497.8 \mathrm{eV}$ ).

The detailed XPS spectra of nickel are presented in Figure 9. The deconvoluted spectra for the initial $\mathrm{ZnNiP}$ samples (Figure 9a), asociated to nickel show the existence of a mixture of $\mathrm{Ni}^{2+}$ and $\mathrm{Ni}^{3+}$ chemical states from the line profile (including satellites) and the position of the Ni2 $p_{3 / 2}$ peak. The characteristic BE values of the $2 p_{3 / 2}$ feature $(853.4,853.5,853.8 \mathrm{eV}) ; 856.1,855.0,855.9 \mathrm{eV})$, the band-like profile of the spectrum, as well as the presence of the associated satelittes at $(857.7,859.9,860.0 \mathrm{eV})$ are the fingerprints of a mixture of $\mathrm{NiO}$ and $\mathrm{Ni}_{2} \mathrm{O}_{3}$. $\mathrm{The}$ relative concentrations of nickel in these two different chemical states are $40 \% \mathrm{Ni}_{2} \mathrm{O}_{3}$ and $60 \% \mathrm{NiO}$. For all samples corroded we noticed that do not occur compositional changes, but only small decrease in the concentration (Table 4 and Fig.9b)

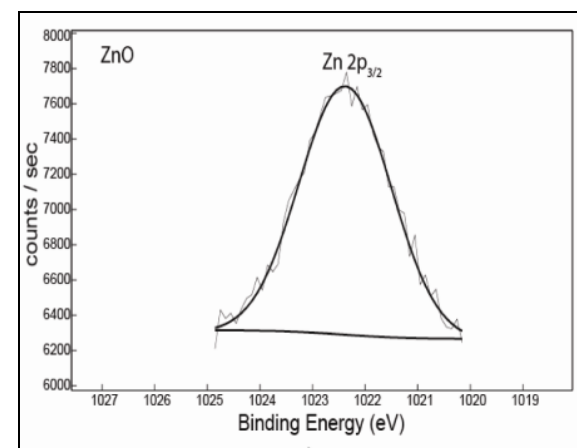

a)

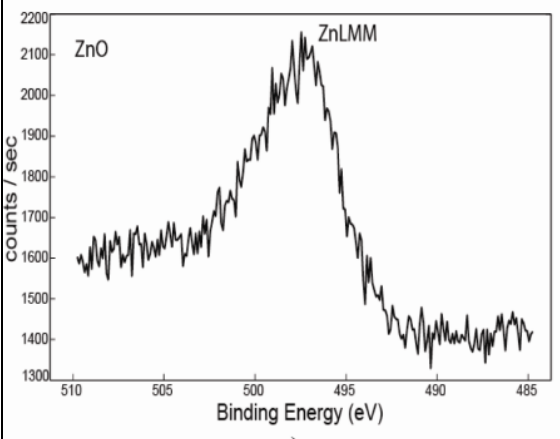

c)

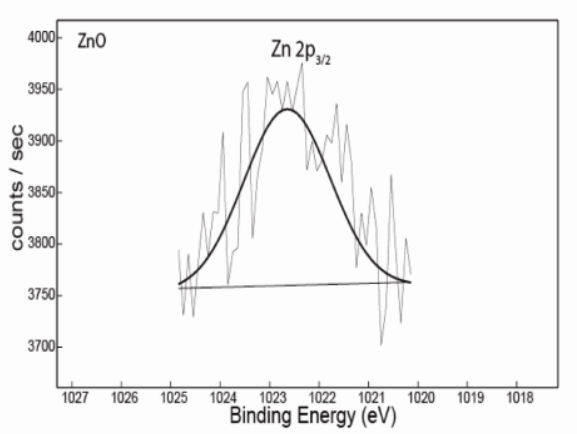

b)

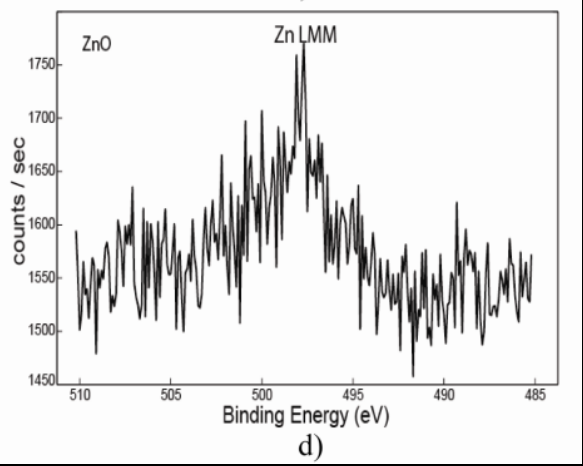

Fig. 8. The peak deconvolution of spectra of $\mathrm{Zn} 2 \mathrm{p}_{3 / 2}$ and $\mathrm{Zn} \mathrm{LMM}$ Auger transition before $(\mathrm{a}, \mathrm{c})$ and after corrosion $(b, d)$ in the used ILs

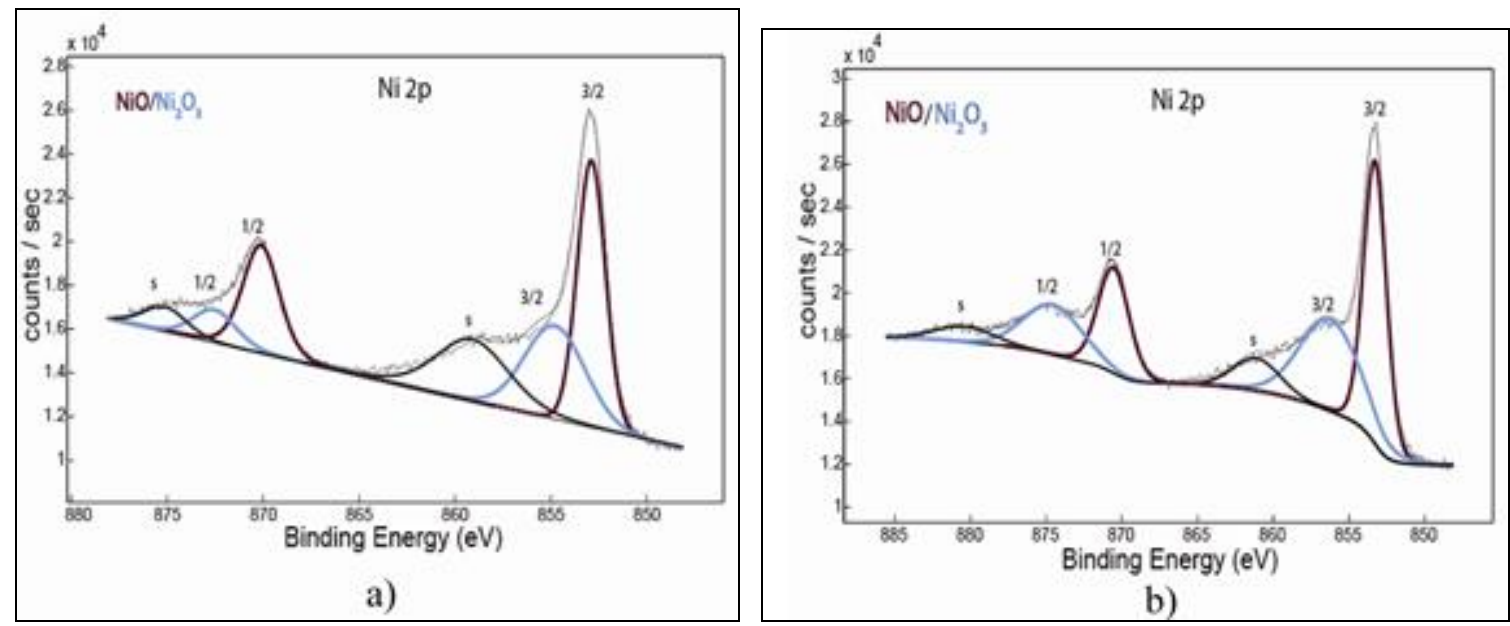

Fig. 9. The peak deconvolution of spectra of Ni2p before (a) and after corrosion (b) in the used ILs.

The detailed XPS spectra of phosphorus P2p (Figures 7 and 10) are very noisy in both initial and corroded states of the sample as a result of the tiny relative concentration of this element in the $\mathrm{Zn}-\mathrm{Ni}-\mathrm{P}$ thin films. The spectra show two different peaks for the initial and corroded sample $\mathrm{ZnNiP}(1)$ with a peak appeared at a binding energy of $\sim 130.1$ $130.2 \mathrm{eV}$ which is detected as elemental phosphorus $\left(\mathrm{P}^{0}\right)$. The phosphorus signal at the binding energy of $133.2 \mathrm{eV}$ can be assigned to an organic combination of phosphorous ( $\mathrm{P}_{\text {organic }}$ ), especially in $\mathrm{ZnNiP}(2)$ and $\mathrm{ZnNiP}(3)$ samples, proving the excepted citrate complexes in the deposition bath. 


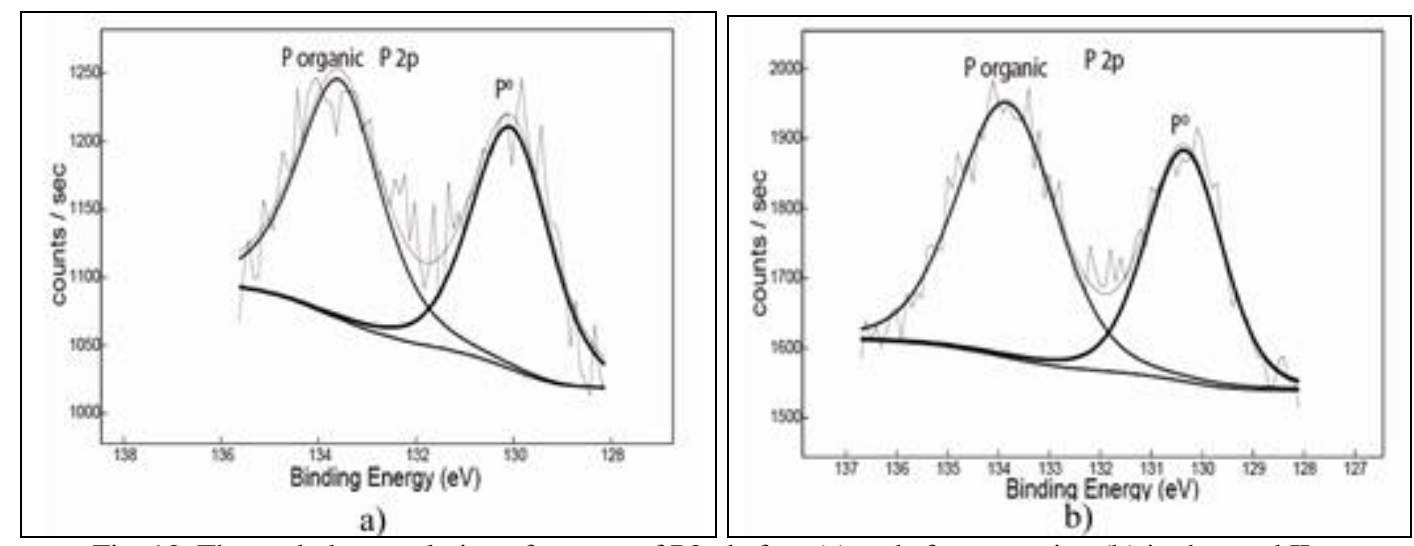

Fig. 10. The peak deconvolution of spectra of P2p before (a) and after corrosion (b) in the used ILs.

In the case of the all corroded samples it can be noted a signal given of nitrogen (Figures 6 and 7c). As can be seen in the detailed XPS spectrum for nitrogen (N1s), Figure 11 is very noisy as a result of the tiny relative concentration of this element. The first peak is attributed to the oxidation state $\mathrm{N}^{3-}$ (nitride). After deconvoluted spectrum it was found that the second peak is a part of an organic matrix, which may be derived from the ionic liquid used as the corrosion medium. The characteristic BE values of the N1s feature 398.1, 398.8, 398.2 eV (Table 5). Nitrogen is segregated to the alloy surface where it forms a relatively stable interstitial nitride phase. Thus we can conclude that the presence of $\mathrm{N}$ leads to anticorrosive protection for all three samples, by reducing the corrosion currents. This also correlates with the micrographs results.

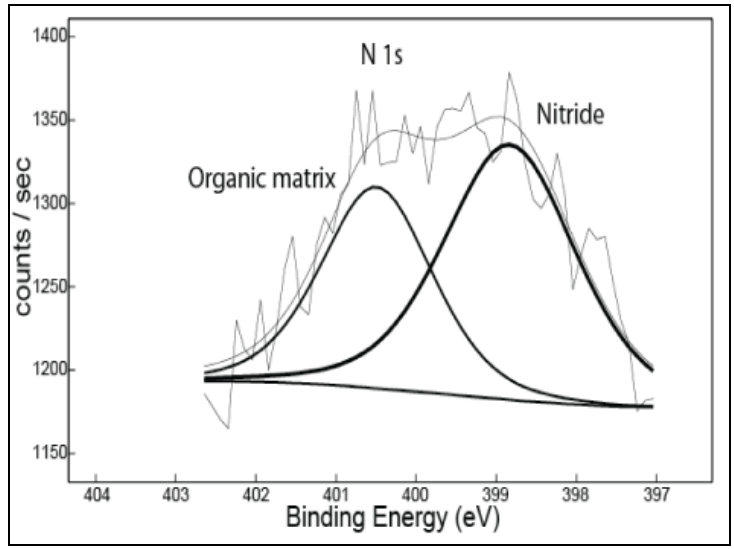

Fig. 11. The peak deconvolution of of N1s in the used ILs

\section{Conclusions}

$\mathrm{ZnNiP}$ thin films were successfully prepared on low carbon steel substrate by electroless deposition from hypophosphite low alkali aqueous bath. The thin film is compact, uniform and has microcrystalline phases. EDAX elemental analysis confirmed the formation of $\mathrm{ZnNiP}$ coating with high $\mathrm{Ni}$ content. The XPS results demonstrated that the incorporation of $\mathrm{Zn}$ in the $\mathrm{Ni}-\mathrm{P}$ electroless thin layer is possible using this electroless process. It also has been demonstrated that $\mathrm{ZnNiP}$ alloys show good corrosion resistance in choline chloride based eutectic ILs relative to aqueous sodium chloride solutions, although corrosion in this case occurred at a higher temperature $(353 \mathrm{~K})$ than that in the aqueous $\mathrm{NaCl}$ solution $(298 \mathrm{~K})$. Also taking into account the value of the corrosion rate of the control steel in the two ILs in the study, it was found that the ChCl-ethylene glycol (Ethaline100) is ultimately more corrosive than ChCl-urea (Reline200).

This good resistance to corrosion is given both by the passive layer of nickel oxides formed on the surface of $\mathrm{ZnNiP}$ thin films and by the incorporation of nitrogen into the passive layer structure, which reduced the corrosion current.

Acknowledgments: This work was carried out within the programm: "Electrode processes, materials for electrochemical processes and corrosion" of the "Ilie Murgulescu" I.C.P and has been supported by the Romanian Ministry of Education and Science, Partnership Program [Project nr. 72-221/2008-2011] and EU(ERDF)-Romanian Government that allowed for acquisition of the research infrastructure under POSCEEO2.2.1-INFRANANOCHEM [project nr.19/01.03.2009]. Authors equally contributed to this work.

\section{References}

1. HOLBREY, J.D., SEDDON, K.R. Clean Prod. Proc., 1, 1999, p. 223.

2. WELTON, T. Chem. Rev., 99, 1999, p. 2071.

3. ENDRES, F. ChemPhysChem, 3, 2002, p. 144. 
4. LIN, Y.F., SUN, I.W. Electrochim. Acta, 44, 1999, p. 2771.

5. POPESCU, A.M., DONATH, C., NEACSU, E.I., SOARE, V., CONSTANTIN, V. Rev. Chim.(Bucharest), 67, no. 6, 2016 , p. 1076.

6. TAKAHASHI, S., KOURA, N., KOHARA, S.,SABOUNGI, M.L,.CURTISS, L.A. Plasmas \& Ions, 2,1999, p. 91.

7. BRENNECKE, J.F., MAGIN E.J. AIChE J., 47, 2001, p. 2384.

8. UE, M., TAKEDA, M., TORIUMI, A., KOMINATO, A., HAGIWARA, R., ITO, Y., J. Electrochem. Soc., 150, 2003 , p. A499.

9. BALDUCCI, A., BARDI, U., CAPORALI, S., MASTRAGOSTINO, M., SOAVI, F. Electrochem. Commun., 6, 2004 , p. 566.

10. MOENS, L., BLAKE, D.M., RUDNICKI, D.L., HALE, M.J. J. Sol. Energy. Eng, 125, 2003, p. 112.

11. DURAIRAJAN, A., KRISHNIYER, A., HARAN, B.S., WHITE, R.E., POPOV, B.N. Corrosion, 56, 2000, p. 283.

12. HUANG, Y.S., CUI, F.Z. Surf. Coat. Tech., 201, 2007, p. 5416.

13. WANG, R., YE, W., MA, C., WANG, C. Mater. Character., 59, 2008, p.108.

14. SRIVASTAVA, C., GHOSH, S.K., RAJAK, S., SAHU, A.K., TEWARI, R., KAIN V., DEY, G.K. Surf. Coat. Techn., 313, 2017 , p. 8.

15. REHIM, S.S.A.E., FOUAD, E.E., WAHAB, S.M.A.E., HASSAN, H.H. Electrochim. Acta, 41 1996, p. 1413.

16. DURAIRAJAN, A., HARAN, B.S., WHITE, R.E., POPOV, B.N., J. Electrochem. Soc., 147, 2000, p. 1781.

17. BOUANANI, M., CHERKAOUI, F., FRATESI, R., ROVENTI, G., BARUCCA, G.J. Appl. Electrochem., 29, 1999 , p. 637.

18. *** ASTM G1-03, Standard practice for preparing, cleaning, and evaluating corrosion test specimens, PA, ASTM International, 2011, https://doi.org/10.1520/G0001-03R11.

19. KANG, H.B., BAE, J.H., LEE, J.W., PARK, M.H., LEE, Y.C., YOON, J.W., JUNG, S.B., YANG, C.W. Scripta. Mater., 60, 2009 , p. 257.

20. MOULDER, J.F., STICKLE, W.F., SOBOL, P.E., BOMBEN, K.D., Handbook of X-ray photoelectron spectroscopy. CHASTAIN, J., KING JR R.C. (eds.). Minnesota, Physical Electronics Inc, 1995.

21. GROSVENOR, A.P., BIESINGER, M.C., SMART, R.S.C., MC INTYRE, N.S. Surf. Sci., 600, 2006, p. 1771.

22. Yang, L., Li, J., Zheng, Y., Jiang, W., Zhang, M. J. Alloys Compd., 467, 2009, p. 562.

23 REVIE, R.W. (ed.). Uhlig's Corrosion Handbook, 3-rd ed., John Wiley \& Sons Inc, NJ, 2011.

24. Zhang, W.X., He, J.G., Jiang, Z.H., Jiang, Q., Lian, J.S. Surf. Coat. Technol., 201 2007, p. 4594.

25. ASTM D3359-09e2, Standard Test Methods for Measuring Adhesion by Tape Test,ASTM International, West Conshohocken, PA, 2009, https://doi.org/10.1520/D3359-09E02.

26. VEERARAGHAVAN, B., HARAN, B., KUMARAGURU, S.P., POPOV, B., J. Electrochem. Soc., 150, 2003 , p. B131.

27. REVIE R.W., UHLIG H.H. Corrosion and Corrosion Control. An Introduction to Corrosion Science and Engineering, fourth ed., John Wiley \& Sons Inc., NJ, 2008.

28. PERISSI, I., BARDI, U., CAPORALI, S., LAVACCHI, A. Corros. Sci., 48, 2006, p. 2349.

29 PERISSI, I., CAPORALI, S., FOSATTI, A., LAVACCHI, A. Corrosion resistance of metallic materials in ionic liquids.chapter 12 in: Advanced in Chemistry Reseach vol.6, Taylor JC, (ed.)., NOVA Science Publishers Inc., NY, 2011.

30. RAHMAN, M.J., SEN, S.R., MONIRUZZAMAN, M., SHOROWORDI, K.M., J. Mech. Eng. (Trans. of the Mech. Eng. Div., The Institution of Engineers, Bangladesh), ME40, 2009, p. 9.

31 LEE, H.L., FLYNN, N.T., X-ray photoelectron spectroscopy.chapter 11 in: Handbook of Applied Solid State Spectroscopy. VIJ, D. (ed.). MA, Springer, 2006.

$\overline{\text { Manuscript received: } 18.12 .2018}$ 